anales de psicología / annals of psychology

2020, vol. 36, $\mathrm{n}^{\circ} 1$ (january), 30-38

https://doi.org/10.6018/analesps.348441
(C) Copyright 2020: Editum. Servicio de Publicaciones de la Universidad de Murcia. Murcia (Spain) ISSN print edition: 0212-9728. ISSN on line edition (http://revistas.um.es/analesps): 1695-2294

On line edition License Creative Commons 4.0: BY-NC-ND

\title{
Health and burnout of home health care assistants: Impact of a training intervention
}

\author{
Javier Saavedra ${ }^{1}$, Lara Murvartian ${ }^{2}$, and Natividad Vallecillo ${ }^{2}$ \\ 1 PhD, Associate Professor, Dep. Experimental Psychology, University of Sevilla (Spain) \\ 2 Assistant Researcher, Dep. Experimental Psychology, University of Sevilla (Spain)
}

\begin{abstract}
Título: Salud y burnout de cuidadores profesionales a domicilio: Impacto de una intervención formativa.

Resumen: Existe una creciente necesidad de cuidados en los países desarrollados, por lo que el número de cuidadoras a domicilio ha aumentado de manera exponencial. La literatura ha señalado que este grupo profesional tiene un alto riesgo de sufrir una gran variedad de problemas de salud. A pesar de su importancia, no hay cursos de entrenamiento descritos para ellas. Este estudio describe el diseño de un curso psicoeducativo para un grupo de cuidadoras y muestra los resultados de un estudio pre-post para evaluar su efectividad considerando las siguientes variables: el estado psicosocial de salud, el agotamiento y los pensamientos disfuncionales sobre el cuidado. Una ANOVA de medidas repetidas se utilizó siempre que fue posible y la prueba de Wilcoxon o la prueba de Mann Whitney se usaron como pruebas no paramétricas. Los pensamientos disfuncionales se redujeron después del curso, siendo el tamaño del efecto mediano a grande. La disfunción social se redujo solo en el grupo de mujeres que también eran cuidadoras familiares. Llegamos a la conclusión de que las cuidadoras profesionales pueden beneficiarse de una breve capacitación.
\end{abstract}

Palabras claves: Cuidadoras; Burnout; Salud; Intervención Psicoeducativa; Cuidadoras a domicilio; Demencia.

\section{Introduction}

\section{Home health care assistants in the frame of a care crisis}

A greater life expectancy, the prevalence of chronic diseases and such socio-cultural changes as the logical incorporation of women into the workplace, who were traditionally dedicated to caregiving tasks in Mediterranean countries, imply an exponential increase of those tasks related to the care for dependent people. Some authors have called this a "Care crisis" (Jagger, 2017). These facts pose a major challenge to the social and health systems in some countries.

Due to the growing need for care, there has been a proliferation of female caregivers, many of them at home, in some cases organized by the social services of local councils and in other cases by private companies. In most cases, these caregivers have a low training level and some of them are or have been family caregivers as well. In fact, home care for the elderly or chronically ill has become one of the employment niches for vulnerable sectors such as migrant women with a low education level and no previous work experience, especially after the European economic crisis. Thus, Home Health Care Assistants (HHCA) can be defined as caregivers who work at patients' homes. Mostly, they are women without formal training and they care for people with dementia

* Correspondence address [Dirección para correspondencia]: Javier Saavedra. University of Sevilla. Dep. Experimental Psychology. C/Camilo José Cela, s/n, 41018, Sevilla (Spain). E-mail: fjsaavedra@us.es (Article received: 4-11-2018; revised: 28-1-2019; accepted: 2-7-2019)
Abstract: There is a growing need for care in developed countries, so the number of home health care assistants has increased exponentially. The literature has pointed out that this professional group is at high risk for a variety of health problems. Despite its importance, there are no described specific training interventions for it. This study describes a course for a group of female caregivers. A pre-post study is carried out to evaluate its effectiveness considering the following variables: the psychosocial state of health, the burnout and the dysfunctional thoughts about caregiving. The repeated measures ANOVA was used whenever possible and the Wilcoxon-test or the Mann Whitney-test were used as nonparametric tests. Dysfunctional thoughts were reduced after the course, being the effect size medium to large. Social dysfunction was reduced only in the group of women who were also family caregivers. We conclude that professional caregivers can benefit from brief training.

Keywords: Caregivers; Burnout; Health; Psycho-educative intervention; Home Health Care Assistant; Dementia.

and a serious lack of autonomy. Hewko et al. (2015) define this work context as marginal. HHCA are the ones receiving the lowest salary, officially working fewer hours and getting the least benefits from their work, even compared to other health professionals. It is not surprising, therefore, that they are considered an example of precarious employment.

The growing presence of these female professional caregivers at homes, nursing homes or hospitals, is not commensurate with the recognition they receive for their work, as they are, to some extent, invisible, yet actually ubiquitous, both to the scientific community and to political leaders (Hewko et al., 2015). In the UK, for example, it is estimated that there are up to 1.5 million female caregivers, as opposed to some half a million registered nurses working in various sectors (Schneider, 2017). In Spain, in 2007, half of the people receiving professional care received it at home. Considering that most of the care given is informal and there is a large amount of undeclared work, doubtlessly, home is the most frequent context of care (European Commission, 2009).

\section{Caregivers and health}

It is clearly established that the absolute majority of people who care for relatives are women (IMSERSO, 2005) and that they have worse health themselves. They show a greater number of anxiety and depression symptoms, various somatic symptoms such as back pain, and a higher prevalence of some chronic diseases (Colombo, Llena-Nozal, Mercier \& Tjadens, 2011; Saavedra, Bascón, Arias, Calderón \& Mora, 2013). The limited literature available indicates that caregiv- 
ers with burnout are at a greater risk than their more professionalized counterparts -nurses-, even if they work in the same context (Gerhard, 2000). In fact, it has been found that the burnout suffered by these HHCA is particularly high and it can lead to significant health issues in a medium to long term. For example, Fujiwara, Tsukishima, Tsutsumi, Kawakami and Kishi (2003) found in a sample of HHCA in Japan that interpersonal conflicts with clients and family members were significantly related to emotional exhaustion and depersonalization factors of the MBI burnout scale. These conflicts are not as frequent or as intense in caregivers who work in nursing homes or health centers without direct and continuous contact with family members.

\section{Training programs for caregivers}

One of the most relevant aspects of the scarce literature on female professional assistant caregivers (both at home and in nursing homes and social-health facilities) is the need for training. Due to their low education level, an optimal training design and the study of training effectiveness are essential. This is not only for the sake of an increased quality and continuity of care, but also as a prevention of the stress and health problems that the emotional work inherent in these tasks can entail (Bayley, Scales, Lloyd, Schneider, \& Jones, 2015; Fujiwara et al., 2003). The heterogeneity of female HHCA in terms of their administrative framework (social services of public administrations, private entities, undeclared work, etc.) makes it extremely difficult to design training programs for them. It is not surprising that Hewko et al. (2015), in their extensive literature review, state that they did not find any studies describing a training program for female HHCA.

An updated review of the literature from the last three years in the Web of Science database on the subject of existing training courses or interventions for home health care assistants was conducted. Out of a total of 145 articles, a sample of 13 focused on our target.

According to the studies analyzed, there are two main problems associated with home health care assistants. In the first place, there is a high variability of educational levels, inadequate training according to the workplace demands and the educational interventions carried out have been ad-hoc (Karacsony, Chang, Johnson, Good, \& Edenborough, 2018). The fact that many of them work without being trained (Craftman, Grundberg, \& Westerboth, 2019) is often due to workplace conditions such as low wages and time pressure (Wilberforce et al., 2017; Estabrooks, Squires, Carleton, Cummings, \& Norton, 2015), as well as the lack of standardized training programs that give access to such jobs, as it occurs with unregulated care providers in Canada (Kelly, \& Bourgeault, 2015). And in the second place, they suffer from burnout. Positive reappraisal, one cognitive emotion regulation strategy, was significantly associated with depersonalization, and shorter sleep duration was associated with significantly greater depersonalization (Bamonti et al., 2019).
All of these problems mentioned above are important because they decrease workers' health and retention, their job satisfaction and the quality of care (Ravenswood, Douglas, \& Haar, 2018; George, Hale, \& Angelo, 2017; Zhang, Punnett, \& Nannini, 2017; Estabrooks et al., 2015). For these reasons, it is necessary to create educational programs and interventions on reducing dysfunctional coping strategies, learning healthy sleep practices, increasing self-efficacy (Coates \& Fossey, 2019) and improving communication (George et al., 2017). Islam, Baker, Huxley, Russell, \& Dennis (2017) highlight the importance of dementia training in care homes, in order to reduce stress in professionals, especially in nursing and larger care homes.

The solution proposed by the Ministry of Training, Colleges and Universities of Canada for the lack of standardization of the educational program that gives access to these jobs included focus groups to concretize the demands of the professionals and the creation of a technical working group (Kelly, \& Bourgeault, 2015). However, none of the studies found carries out or propose a specific intervention program for HHCA in particular. Regarding effective intervention programs, we found one on improving the engagement of Nursing Home Resident-Staff (Hartmann et al., 2018), the Reablement service, a person-centered approach that strengthens their professional identity, as they encourage and teach the elderly how to take care for themselves (Hjelle, Skutle, Alvsvag, \& Forland, 2018). As we can see, none of these is aimed especially at improving stress coping strategies in order to prevent burnout in HHCA and there are no programs aimed at training basic knowledge about aging and dementia, which is why we propose the following intervention program.

Therefore, it is necessary to seek information of similar training programs addressed to other populations. There are training programs addressed to the staff of care homes or nursing homes for people with dementia that could provide us with some information about how to design training programs for HHCA. According to a systematic review (Spector, Revolta and Orrell, 2016), the main aims of these staff interventions are communication, management of challenging behaviors, person-centered approaches, improving resident mood and quality of life as well as improving staff knowledge and changing its attitudes. These interventions clearly improved knowledge; however, stress and burnout seemed not to be improved in a significant way (Spector et al., 2016). On the other hand, there is some partial evidence of the effectiveness of stress management courses for family caregivers (Losada et al., 2006; Ruiz-Robledillo \& MoyaAlbiol, 2015; Saavedra, et al., 2013). The aim of these courses or workshops is to provide family caregivers with strategies and resources to cope with the stress that caregiving tasks entail. Among other results, it has been found that stress management training courses that include cognitivebehavioral techniques reduce anxious-depressive symptoms and dysfunctional thoughts about care, which indirectly affect the health status of caregivers. The reduction of dys- 
functional beliefs about care is especially important in Mediterranean or Latin American populations, on which "familialism" is dominant (Losada et al., 2006).

Given the lack of studies describing and evaluating training programs for female HHCA (Schneider, 2017) and the vulnerability in terms of health and stress of this population, the aim of the present study is to analyze the impact of the training intervention on health, burnout and irrational beliefs by means of a pretest - posttest design. Moreover, the following can be considered sub-aims: firstly, to describe the organization of a training course focused on communication, stress management and basic knowledge on aging and dementia for female HHCA; secondly, to provide descriptive data on health, burnout, and irrational beliefs about participants' care tasks and to explore the associations between these three variables.

\section{Method}

\section{Participants}

In Table 1, the basic socio-demographic information of the study's participants is described. The course being evaluated involved 29 women with an average age of 47.32 ( $s d$. 9.7) and an average of 8.35 years of experience on profes- sional care (sd. 6.2). A percentage of $82.76 \%$ were married women or living with their couples; whilst $17.24 \%$ were single. All the women were Spanish, except from one woman who was Romanian. Among them, $65.5 \%$ had completed or started but not finished compulsory education, $20.7 \%$ had received vocational training, $6.9 \%$ had completed noncompulsory secondary education and $6.9 \%$ had a University degree. Only five women said that they had some specific health academic training (clinical assistant, nutrition technician, etc.). The vast majority of women reported that their patients suffered from different dementia processes ( $\mathrm{Al}_{\mathrm{z}}$ heimer's, Parkinson's, Huntington's Syndromes, etc.). They also reported working with elderly people with serious physical difficulties and some children with developmental delays. A percentage of $75.9 \%$ (22) were not family caregivers while working as HHCA and seven of the participants were family caregivers at home. Significant differences were not found between family and not-family caregivers regarding age, years of professional experience and education level. Those women who were working as HHCA in the town of Gines and who volunteered at the announcement of the first course were included in the study. Those women without work experience as HHCA in the last six months were excluded from the research.

Table 1. Socio-demographic variables.

\begin{tabular}{|c|c|c|c|c|}
\hline Socio-demographic variables & Media & $S D$ & $N$ & $\%$ \\
\hline Age & 47.32 & 9.7 & 29 & \\
\hline Years of experience on professional care & 8.35 & 6.2 & 29 & \\
\hline \multicolumn{5}{|l|}{ Marital status } \\
\hline Living with their couples & & & 24 & 82.76 \\
\hline Singles & & & 5 & 17.24 \\
\hline \multicolumn{5}{|l|}{ Educational level } \\
\hline Completed or started but not finished compulsory education & & & 19 & 65.5 \\
\hline Vocational training & & & 6 & 20.7 \\
\hline Completed non-compulsory secondary education & & & 2 & 6.9 \\
\hline University degree & & & 2 & 6.9 \\
\hline \multicolumn{5}{|l|}{ Type of caregiver } \\
\hline Carer as HHCA & & & 22 & 75.9 \\
\hline HHCA and family caregiver & & & 7 & 24.1 \\
\hline
\end{tabular}

Almost all of the women said that they expected an increase in their knowledge and professional training from the course. Six female employees went beyond purely theoretical or technical aspects and they expected to understand how users feel, to improve their skills in dealing with patients or, for example, to share their experiences with other colleagues.

Every participant read an information sheet describing the aims of the study. When filling the questionnaire, they were giving their consent to participate. Participation was voluntary and confidentiality was guaranteed by researchers. The Gines Town Hall was informed of the research project and professionals in charge of participants (employees) set a commission up and approved the research protocol in accordance with ethical requirements.

\section{Instruments}

In addition to a questionnaire with socio-demographic information, the 28-item General Health Questionnaire (GHQ-28) (Goldberg \& Williams, 1996), the Dysfunctional Thoughts about Caregiving Questionnaire (CPD) (Losada et al., 2006) and the Maslach Burnout Inventory for Health Professionals (MBI-HSS) (Maslach, Jackson \& Leiter, 1996) were used.

The GHQ has been widely used in epidemiological research for decades and it has proven its reliability and validity in the analysis of psychosocial health in numerous samples around the world. GHQ-28 (Goldberg \& Williams, 1996) is composed of 28 items with a 4-point Likert scale about the psychosocial health in the last two weeks. For example, the 
fifth item is the question "have you had headaches?". GHQ28 presents four factors: somatic symptoms, anxiety, social dysfunction and depression. Higher scores are interpreted as worse psychosocial health. The Spanish version of GHQ-28 was used (Lobo, Pérez-Echevarría, \& Artal, 1986). We obtained the following internal consistency: the total GHQ-28 score showed a Cronbach's alpha of .842; the somatic symptoms scale, .706; the anxiety scale, .879; the social dysfunction scale, .664; and the depression scale, .952.

CPD is designed to study dysfunctional thoughts about caregiving. It has two factors, devotion-isolation and selfcommitment-responsibility, as well as a total score (Losada et al., 2006). The CPD (Losada et al., 2006) consists of a 22item questionnaire with a 5-point Likert scale of agreement. Items consist of social beliefs about caring and participants should respond in accordance with their level of agreement with these social beliefs. For instance: "Only the closest people to an ill family member know how to really take good care of them". Although it is a relatively young test, it has proven acceptable validity and reliability. As in the GHQ, higher scores are interpreted as more dysfunctional thoughts. The Cronbach's alpha of the overall score obtained in our study was .921. The internal consistency of the two factors is also high: .907 for self-commitment-responsibility and.769 for devotion-isolation.

The MBI-HSS (Maslach, Jackson \& Leiter, 1996) is a $22-$ item questionnaire composed of three factors: emotional exhaustion, depersonalization and personal achievement. For example, the second item of the MBI-HSS states "I feel tired at the end of the working day". The frequency version, which was used for this study, has a 7-point Likert scale ranging from 0 ("Never") to 6 ("Every day").The MBI-HSS is the reference questionnaire for the burnout study on health workers. Its adaptation to Spanish has been widely used in different health contexts with good results (GilMonte \& Peiró, 1997). In our study, in the first factor we obtained a Cronbach's alpha of .881; in the second factor, an insufficient consistency of .437; and in the last factor, of .778 .

\section{Procedure and context}

The course was held in the town of Gines $(11,000$ inhabitants), in the province of Seville (Andalusia, Spain). Before the course was held, several meetings were carried out between the town councilors on which HHCA depended and researchers. The course was defined as a psycho-educational intervention with the following objectives: acquisition of knowledge related to care tasks and promotion of staff physical and psychological well-being through the acquisition of stress management tools. The course was advertised to HHCA working in the Gines Town Hall and the first received applications were accepted in the first edition of the course.

The intervention was designed by the first and second authors of this study after several interviews with social ser- vices' professionals in the town of Gines. A systematic revision of the literature about psychosocial interventions with HHCA was carried out. Due to the lack of studies assessing interventions specifically with HHCA, the intervention was based on programs addressed to similar populations. For instance, the intervention programs on the caregivers of people with autism spectrum disorder's health (Ruiz-Robledillo \& Moya-Albiol, 2015) or programs on improving the psychological well-being amongst family caregivers of people with dementia (Losada, Montorio, \& Márquez, 2006; Saavedra, et al., 2013). As we can see in table 2 , in accordance with the activities carried out, the program can be considered a cognitive-behavioral intervention. In this sense, the core of the intervention is focused on discussing irrational beliefs, communication skills and stress-coping strategies. This intervention could be classified as a high intensity training program according to Spector et al. (2016).

Table 2. Contents of the sessions.

\begin{tabular}{ll}
$\begin{array}{l}\text { Session } \\
\text { number }\end{array}$ & Description \\
$\begin{array}{l}\text { Starting } \\
\text { Session }\end{array}$ & Presentation and pre-test. \\
\hline 1 & $\begin{array}{l}\text { Basic information on normal aging and dementia: Alz- } \\
\text { heimer's, Parkinson's and other syndromes I }\end{array}$ \\
2 & Basic information on normal aging and dementia: Alz- \\
& heimer's, Parkinson's and other syndromes II \\
3 & Stress response: functional and dysfunctional aspects \\
4 & Negative emotions in caregiving work \\
5 & Coping strategies and problem-solving techniques \\
6 & Communication and social skills training I \\
7 & Communication and social skills training II \\
8 & Irrational beliefs associated with caregiving \\
9 & Conflict management \\
10 & Social support, self-esteem and psychological well-being \\
11 & Mourning \\
12 & Resources for the empowerment of users and families \\
Closing & Closure, evaluation and post-test.
\end{tabular}

Session

The two editions of the intervention program consisted on 13 sessions, of 2 hours each, once a week (see table 1). The first edition started on January, 17th, 2017 and continued until April, 11th, 2017 and it is the one being evaluated in this paper. The second edition of the intervention, which was not previously planned, was carried out at the special request of the Gines Town Hall and the HHCA who were left out of the first edition. A Psychology School professor, a psychologist with a scholarship from the Spanish Ministry of Education, Culture and Sports, two psychologists from the Social Services of the Gines Town Council and a social worker from the same institution participated in the implementation of the program.

\section{Design and Statistical Analysis}

Firstly, positive cases were identified in the GHQ with a cut-off point of $4 / 5$ suggesting participants at risk of psycho- 
logical disorder. The associations between the three variables in the pretest health (GHQ), irrational thoughts about caregiving (CPD) and burnout (MBI), as well as the age scores, were explored using the Spearman's correlation.

Percentages of high burnout levels were also found according to the standardized cut-off points in Spain of the MBI (Gil-Monte \& Peiró, 2000).

A pretest-posttest design was used to explore the effectiveness of the intervention in the participants. The results of the GHQ, CPD and MBI questionnaires were considered dependent variables. The repeated measures ANOVA was performed when the homogeneity tests and the Box's M test allowed it. The contrast between the pre and posttests was defined as an intrasubject variation and the contrast between the group of employees who also took care of their relatives and those who were exclusively professional caregivers was defined as an intersubject variation. When the statistical requirements for the use of this test were not met, we used the Wilcoxon test for intrasubject differences and the Mann Whitney test for intersubject differences as non-parametric tests. As an effect size measurement, we used Eta-square for repeated measures ANOVA and Rosenthal's $r$ for nonparametric tests, recommended by Wasserstein and Lazar (2016), and we expressed it as follows: $r=\mathrm{z} / \sqrt{ } \mathrm{N}$. In order to interpret the effect size, we used the recommendations made by Cohen (1988). Version 22 of the SPSS statistical package was used.

\section{Results}

Associations between Health (GHQ-28), Dysfunctional Thinking (DPC), Burnout (BMI) and other socio-demographic variables

Clinical cases in the pretest were calculated according to cut-off point $4 / 5$ in GHQ-28, obtaining three of them
$(10.33 \%)$, of which two were women who were also family caregivers. Although the difference was not significant using a chi-square test, the effect size was medium (chi $=3.402$, $p$ $=.065, \mathrm{~V}=.369)$. The percentages of high burnout levels according to the normalized cut-off points in Spain of the MBI (Gil-Monte \& Peiró, 2000) were of $3.1 \%$ for the emotional fatigue factor, $16.6 \%$ for depersonalization and 12.5 $\%$ for low self-realization. No significant differences were found between female employees who were also family caregivers and those who were not. The effect sizes were small or very small.

Table 3 shows that the scores of the first GHQ factor (somatizations) correlated significantly with the first CPD factor (devotion-isolation) and with the total CPD score. Moreover, they correlated positively with MBI-HSS factors 1 and 2, emotional exhaustion and depersonalization. However, first GHQ factor correlated negatively with the MBI-HSS personal achievement factor. The correlation intensity in all cases was medium or high, considering the small number of subjects. Therefore, the higher the GHQF1 score (poorer health), the higher the CPD score (higher number of irrational beliefs) and the lower the MBI personal fulfillment factor (lower personal fulfillment). The second factor of the GHQ (Anxiety) also correlated significantly and strongly with MBI factor 1 (emotional fatigue). GHQ factor 3 (social functioning) correlated positively with age. The fourth GHQ factor (depression) correlated positively with emotional fatigue and negatively with self-realization in MBI. They obtained respectively .409 and -.406. These are strong correlations for the number of subjects involved. The full scale of GHQ has a significant high correlation intensity with factors 1 and 3 of the MBI.

Table 3. Spearman correlations between psychosocial health status (GHQ-28), dysfunctional thoughts about caregiving (CPD) and Burnout (MBI).

\begin{tabular}{lcccccccc} 
& CPD1 & CPD2 & Total CPD & MBI1 & MBI2 & MBI3 & AGE & Years working in dependency \\
\hline GHQ1 & $.459 * *$ & -265 & $.388^{*}$ & $.398^{*}$ & $.347^{*}$ & $-.359^{*}$ & -102 & -.142 \\
GHQ2 & -.323 & -.084 & .223 & $.397^{*}$ & .194 & -.175 & -.064 & -.048 \\
GHQ3 & .009 & -.267 & -.160 & .188 & -.173 & -.023 & $.399^{*}$ & -.231 \\
GHQ4 & -.010 & -.155 & -.087 & $.409^{*}$ & .049 & $-.406^{*}$ & .052 & .217 \\
Total GHQ & .220 & -.082 & .084 & $.464 *$ & .152 & $-.390^{*}$ & .142 & -.047 \\
\hline
\end{tabular}
${ }^{*} p<.05 ;{ }^{* *} p<.001$

\section{Pretest-posttest differences}

Table 4 shows the differences between the pretest and posttest averages of the analyzed variables. Also, the results of the Box's M test that allowed or prevented the use of repeated measures ANOVA are shown. 
Table 4. GHQ, CPD and MBI averages in pre and posttest and intra-group (pre-post) contrasts using ANOVA or Wilcoxon Test.

\begin{tabular}{|c|c|c|c|c|c|c|c|}
\hline Effect within groups & $n$ & $\begin{array}{c}\text { Pretest } \\
\text { Mean }(S D)\end{array}$ & $\begin{array}{c}\text { Posttest } \\
\text { Mean (SD) } \\
\end{array}$ & $\mathrm{F} / \mathrm{z}$ & $p$ & $\eta^{2} / r$ & $\operatorname{Mbox}(p)$ \\
\hline Total GHQ & 29 & $.526(.304)$ & $.481(.211)$ & $z=-.528$ & $p=.597$ & $r=.09$ & $\begin{array}{c}13.163 \\
(p=.022)\end{array}$ \\
\hline GHQ1 & 29 & $0.586(0.457)$ & $0.684(0.38)$ & $z=-.65$ & $p=.516$ & $r=.12$ & $\begin{array}{c}9.339 \\
(p=.044)\end{array}$ \\
\hline GHQ2 & 29 & $0.704(0.576)$ & $0.633(0.505)$ & $z=-.366$ & $p=.714$ & $r=.067$ & $\begin{array}{c}10.195 \\
(p=.031)\end{array}$ \\
\hline GHQ3 & 29 & $0.798(0.306)$ & $0.781(0.228)$ & $F=2.113$ & $p=.158$ & $\eta^{2}=.073$ & $\begin{array}{c}8.578 \\
(p=.059)\end{array}$ \\
\hline GHQ4 & 29 & $0.74(0.14)$ & $.084(.21)$ & $z=-.141$ & $p=.888$ & $r=.026$ & $\begin{array}{c}23.194 \\
(p<.001)\end{array}$ \\
\hline Total CPD & 28 & $1.303(.728)$ & $0.886(.455)$ & $z=-3.179$ & $p=.001$ & $r=.59$ & $\begin{array}{c}13.81 \\
(p=.010)\end{array}$ \\
\hline CPD1 & 29 & $1.03(0.776)$ & $0.816(0.497)$ & $z=-1.024$ & $p=.306$ & $r=.19$ & $\begin{array}{c}15.121 \\
(p=.004)\end{array}$ \\
\hline CPD2 & 29 & $1.576(0.745)$ & $0.975(0.463)$ & $F=18.24$ & $p<.001$ & $\eta^{2}=.403$ & $\begin{array}{c}6.906 \\
(p=.112)\end{array}$ \\
\hline MBI1 & 29 & $0.905(0.95)$ & $0.955(0.784)$ & $F=.042$ & $p=.839$ & $\eta^{2}=.002$ & $\begin{array}{c}1.661 \\
(p=.695)\end{array}$ \\
\hline MBI2 & 29 & $0.462(0.789)$ & $0.618(0.675)$ & $F=.957$ & $p=.337$ & $\eta^{2}=.034$ & $\begin{array}{c}5.447 \\
(p=.192)\end{array}$ \\
\hline MIB3 & 29 & $5.37(.820)$ & $4.961(1.243)$ & $z=-1.188$ & $p=.235$ & $r=.22$ & $\begin{array}{c}16.817 \\
(p=.002)\end{array}$ \\
\hline
\end{tabular}

Only two direct effects were found between pre- and post-intervention measures; in both cases, they were related to dysfunctional thoughts about caregiving (DPC). Specifically, after the intervention, the total scale of the CPD and factor 2 (self-commitment-responsibility) decreased with an effect size using the Rosenthal's $r .59$ for the total scale and $\eta$ $=.403$, respectively. No other significant intra-group effects were observed for the analyzed variables. No significant differences were found between the subjects (group of employees who were also family caregivers and group of caregivers who were exclusively professionals).

Figure 1 shows the one significant interaction obtained in the analyses. Specifically, while the GHQ factor 3 score (social functioning) decreased dramatically (improved health) for employees who were also family caregivers after the intervention, exclusively professional caregivers slightly increased their score. This interaction is significant with an $\mathrm{F}_{(1,29)}=5.88, p=.022, \eta=.079$. The effect size in this case can be considered as medium high. Although the lack of main effects suggests that there is not a significant worsening of health in the not-family caregivers' subsample, a pairsample t-test was executed in order to check this out. The result of this analysis was not significant: $t_{(21)}=-1.262, p=.26$.

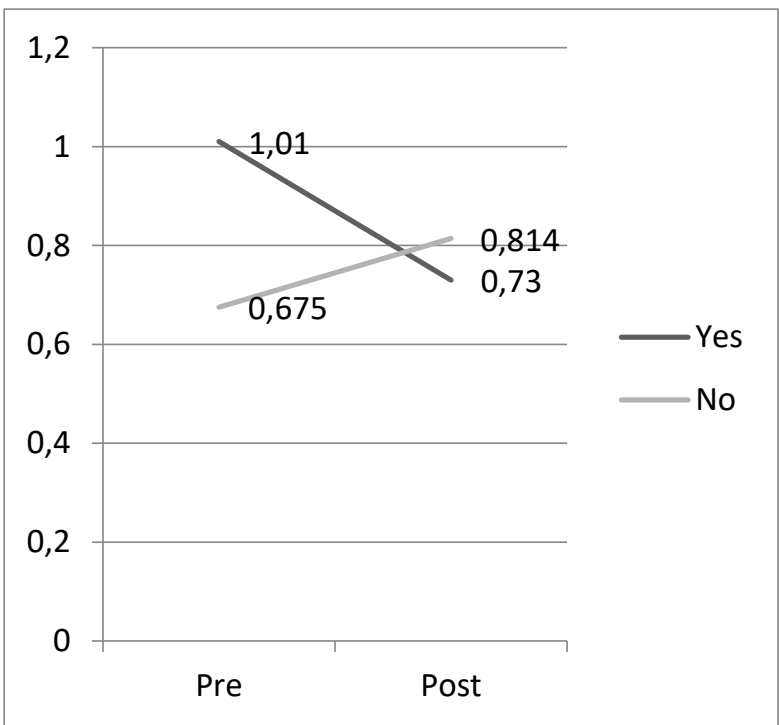

Figure 1. Significant interaction $(p<.05)$ between the intervention (prepost) and family caregiver variables (yes/no).

\section{Discussion}

The sociodemographic data on caregivers and patient types in our sample are similar to those from other research studies. However, it is important to point out two aspects. The first one is that there is only one immigrant woman in our sample. The second one is that the female caregivers worked for a municipal authority, either directly or through a company employed by the municipal authority. 
The correlations between GHQ, CPD and MBI factors are consistent with the expectations. The association between GHQ and the emotional fatigue factor of the MBI is particularly high, indicating serious psychological problems that can lead to various short-term pathologies.

Clinical cases in GHQ-28, according to cut-off point 4/5, are low: only $10.33 \%$. This is similar to the percentage reached by female professional caregivers in other studies, $13.9 \%$, and very far from the percentages reached by exclusive samples of family caregivers, $50 \%$ (Saavedra, Bascón, Rojas \& Sala, 2014). Although not significant, the effect size suggests that women who are also family caregivers are at a higher risk (Colombo et al., 2011). The scores in the CPD are similar to those obtained by other samples of women who are exclusively professional caregivers (Saavedra et al., 2014) and slightly lower than those obtained by female family caregivers (Losada, Montorio, Izal, \& Márquez, 2006). The results of emotional fatigue and depersonalization, factors 1 and 2 of the MBI, are very low according to both the original criteria of Maslach, Jackson and Leiter (1996) and the criteria of Gil-Monte and Peiró's Spanish adaptation (2000). In the same sense, the personal achievement score, factor 3 of the MBI, is high according to cut-off points. These positive results differ from those of other studies with samples of professional female caregivers at home (Fujiwara et al., 2003) and clearly improve other health professionals' scorings in Spain (Grau, Suñer, \& García, 2005).

The better health outcome of professional caregivers over family caregivers suggests that the first group is less homogeneous than the second one, which is clearly at health risk. In the former, factors such as the type of employment relationship, stability, work context (home or residential) and previous social vulnerability (e.g., being an immigrant) may be essential in determining health risk. For example, there is evidence that Latin American immigrant female caregivers in Spain suffer from very poor physical and emotional health (Bover et al., 2014). In our case, the sample's job conditions and sociodemographic factors could explain the GHQ and MBI good results.

The case of the group of seven family caregivers in our sample who also work as professional carers is a special one. On the one hand, it is possible to think that the accumulation of care tasks could be harmful. However, on the other hand they may be able to benefit from their job in terms of psychological health and social relationships. Work has been, for decades, a recognized source of well-being and selfesteem (Bartley, 1994). It is reasonable to think that the work context may be psychologically positive for family caregivers (Saavedra et al., 2014).

It is important to differentiate between those family caregivers who can share their tasks and, therefore, they can also work, and primary family caregivers. These are the family's sole or supreme caregivers, and provide what the Organization for Economic Cooperation and Development (OECD) has called High Intensive Caring because they spend more than 20 hours per week on caregiving as primary caregivers
(Colombo et al., 2011). Primary family caregivers have the highest risk to suffer psychological disorders.

Overall, the intervention had an immediate impact on cognition (beliefs), while in terms of health and emotions (GHQ and MBI) the impact was very limited. In the same line, the systematic review carried out by Spector et al. (2016), showed that the majority of interventions' results do not report a significant impact on burnout. However, despite the already positive baseline data, the intervention carried out reduces the score of dysfunctional thoughts with a very large effect size. These cognitive changes could lead to health improvement by facilitating the use of more adaptive coping strategies and approaches in the long term.

Although there were not main effects in health outcomes (GHQ), a significant interaction in the GHQ3 factor, that assesses social dysfunction, was found. The intervention seems to improve the GHQ3 factor only in professionals who were also family caregivers. Professional women who also take care of family members are a special group within employed women. This group may benefit from interventions that address the emotional management of caregiving experiences. In this sense, the mere participation in the training course already facilitates communication between the caregivers themselves and the strengthening of self-help processes. Sharing this new social context can be a significant change in women with few or no social spaces other than those of their caregiving tasks. This result indicates that some interventions can be effective only in specific populations. Although there was no significant worsening in the women who were exclusively professional caregivers, the existence of an interaction forces us to be cautious with the possible negative effects of the interventions.

The course was designed to adapt the contents and techniques that the existing literature had indicated to be most effective in their research with female family caregivers combined with specific training aspects. It is possible that a design focused exclusively on managing stress and negative emotions would have had more impact on health variables.

In the closing session, some women stressed the need for a professional framework that distinguishes the specific tasks they have to perform as caregivers, as they stated that there was a difference between what they were supposed to do, at least initially, and what families demanded of them (confusion with domestic roles). Gender issues also emerged during the course, such as the female bias at caregiving employment and the difficulty of delegating certain tasks to male family members. There is no doubt that gender and social power relations are essential for understanding caregiving tasks.

\section{Limitations}

Even though an attempt was made, it was impossible to create a waiting list group to work as a control one. We verified that the women's working conditions had not changed significantly between the pretest and the posttest, but without a control group we cannot rule out that some of the 
changes detected are due to strange variables. Moreover, all tests were self-reporting and the internal consistency of the MBI's depersonalization factor was insufficient. Some studies have found bias in the Spanish Version of the General Health Questionnaire (GHQ12) when the sample is made up of both native and immigrant people (Benitez, van de Vijver, \& Padilla, 2017). Even though we have to consider this warning, in our case we used the extended version of GHQ28 and our sample was very even in cultural terms. Therefore, this bias, in case it exists, would be very small. All instruments used in our study were self-administered. Therefore, in future studies, the use of certain qualitative techniques such as interviews would be convenient to avoid the mono-method bias.

In our study we did not control the number of hours of family caregiving for women who had family responsibilities at the same time. This may explain why we have not achieved significant differences between women using the criteria of a probability less than .05 , although we found a remarkable size effect. The course took place after the end of the working day, so in some cases fatigue became evident. Training within the working day hours would have been more logical, but we understood the organizational and economic difficulties involved with making this possible.

Due to our small sample, the statistical power of our design is limited. In other words, we assume the existence of an important level of type II error and some significant differences with low and medium size effect could not be detected. However, this fact means that our interventions could be even more effective than what our results show. In this sense, our intervention should be considered a pilot testing and we should increase the sample in future evaluations.

Obviously, our sample was not representative of the entire caregiving population as it groups together a sample of caregivers with Spanish nationality and with formal employment directly or indirectly in a public administration. Nor can we rule out any social desirability effects, especially from the results of the MBI, since the course and the evaluation

\section{References}

Bamonti, P., Conti, E., Cavanagh, C., Gerolimatos, L., Gregg, J., Goulet, ...Edelstein, B. (2019). Coping, Cognitive Emotion Regulation, and Burnout in Long-Term Care Nursing Staff: A Preliminary Study. Journal of Applied Gerontology, 38(1), 92-111. doi: 10.1177/0733464817716970

Bartley, M. (1994). Unemployment and ill health: Understanding the relationship. Journal of Epidemiology \& Community Health, 48, 333-337. doi: 10.1136/jech.48.4.333

Bayley, S., Scales, K., Lloyd, J., Schneider, J., \& Jones, R. (2015). The emotional labour of health-care assistants in inpatient dementia care. Ageing and Society, 35, 246-269. doi: 10.1017/S0144686X13000573

Benítez, I., Van de Vijver, F., \& Padilla, J.-L. (2017). An Integrated Approach to Bias in the Spanish Version of the General Health Questionnaire (GHQ-12). European Journal of Psychological Assessment. Advance online publication. http://dx.doi.org/10.1027/1015- 5759/a000395

Bover, A., Taltavull, J.M., Gastaldo, D., Luengo, R., Izquierdo, M.D., Juando-Prats, C., ...Robledo, J. (2014). Quality of life in Latin American took place in the premises of the municipality, the administration responsible of the participants' jobs.

\section{Conclusions}

It is clear that high-intensity family caregivers are those who are at a greater risk. Generally speaking, professional female caregivers like those in our study experience a much lower risk. Even in some cases, work activity can be understood as a protective factor. Our study shows that professional female caregivers can benefit from both training courses and stress management workshops, even if these courses or workshops have a short duration as ours had. In particular, the intervention has been very effective in terms of reducing dysfunctional thoughts about care. We hypothesized that the shortterm reduction of these irrational thoughts could be understood as a cognitive restructuring and lead to the use of more effective coping strategies in the medium term. In this way, the psychosocial health of the participants would improve. In the same way, the improvement of social functioning (GHQ factor 3 ) in women who are also family caregivers would also lead to an improvement in other psychosocial factors. This explanation of our results reflects the cognitive-behavioral therapeutic model applied collectively in psychoeducational workshops.

Home Health Care Assistants' training is often precarious and requires the commitment, as in this case, of the administrations they work for and the collaboration of health and academic institutions. Without the collaboration of these institutions, it is very difficult to design interventions that can both improve the quality of services and prevent health problems. Therefore, policy makers should promote communication between public administrations (e.g. municipalities), health services and the University.

Acknowledgments.- Authors would like to thanks to the Social Wellbeing Delegation of the city council of Gines (Seville) for your collaboration.

immigrant caregivers in Spain. Gaceta Sanitaria, 29(2), 123-126. doi: 10.1016/j.gaceta.2014.09.009

Coates, A. \& Fossey, J. (2019). Self-efficacy in dementia care staff: Experiences from the care home context. Dementia, 18(2), 530-544. doi: $10.1177 / 1471301216682627$

Cohen, J. (1988). Statistical Power Analysis for the Behavioral Sciences (2nd ed) Hillsdale, MI: Lawrence Erlbaum.

Colombo, F., Llena-Nozal, A., Mercier, J., \& Tjadens, F. (2011). Help Wanted? Providing and paying from long -term care. Paris, France: OECD Health Policy Studies.

Craftman, A.G., Grundberg, A., \& Westerbotn, M. (2018). Experiences of home care assistants providing social care to older people: A context in transition. International Journal of Older People Nursing 13(6), doi: 10.1111/opn.12207

Estabrooks, C.A., Squires, J.E., Carleton, H.L., Cummings, G.G., \& Norton, P.G. (2015). Who is Looking After Mom and Dad? Unregulated Workers in Canadian Long-Term Care Homes. Canadian Journal on Aging, 34 (1), 47-59. doi:10.1017/S0714980814000506 
European Commission (2009). Ageing Report: Economic and Budgetary Projections for the EU-27 Member States (2008-2060). Brussels: European Economy. doi: 10.2139/ssrn.1993101

Fujiwara, K., Tsukishima, E., Tsutsumi, A., Kawakami, N., \& Kishi, R. (2003). Interpersonal and Conflict, Social Support, and Burnout among a Home Care Workers in Japan. Journal of occupational Health, 45, 313320. doi: $10.1539 /$ joh.45.313

Gerhard, F. (2000). The relationship between optimism and burnout in nursing assistants (doctoral dissertation). University of Hartford, Hartford, CT.

George, E., Hale, L., Angelo, J (2017). Valuing the health of the support worker in the aged care sector. Ageing \& Society, 37(5), 1006-1024. doi: 10.1017/S0144686X16000131

Gil-Monte, P. R. \& Peiró Silla, J. M. (2000). Un estudio comparativo sobre criterios normativos y diferenciales para el diagnóstico del síndrome de quemarse por el trabajo (Burnout) según el MBI-HSS en España [A comparative study on normative criteria and Differentials for the diagnosis of burning syndrome

for work (burnout) according to the MBI-HSS in Spain]. Revista Psicología del Trabajo Organizaciones, 16(2), 135-49. doi: 10.1590/S141373722002000100003

Gil-Monte, P. R. \& Peiró, J. M. (1997). Desgaste psíquico en el trabajo: el síndrome de quemarse. Madrid, España: Síntesis.

Goldberg, D. y Williams, P. (1996). Cuestionario de Salud general GHQ. Barcelona: Masson.

Grau, A., Suñer, R., \& García, M.M. (2005). Burnout syndrome in health workers and relationship with personal and environmental factors. Gaceta Sanitaria, 19(6), 463-70. doi: 10.1016/S0213-9111(05)71397-2

Hartmann, W.C., Mills, W.L., Pimentel, C.B., Palmer, J.A., Allen, R.S., Zhao, ...Snow, A.L. (2018). Impact of Intervention to Improve Nursing Home Resident-Staff Interactions and Engagement. Gerontologist, 58(4), E291-E301. doi: 10.1093/geront/gny039

Hewko, S.J., Cooper, S.L., Huynh, H., Spiwek, T.L., Carleton, T.L., Reid, S., \& Cummings, G. (2015). Invisible no more: a scoping review of the health care aide workforce literatura. BMC Nursing, 14(38), 1-17. doi: 10.1186/s12912-015-0090-x

Hjelle, K.M., Skutle, O., Alvsvag, H., \& Forland, O. (2018). Reablement teams' roles: a qualitative study of interdisciplinary teams' experiences. Journal of Multidisciplinary Healtchare, 11, 305-316. doi: 10.2147/JMDH.S160480

IMSERSO (2005). Cuidado a las personas mayores en los hogares españoles. Madrid, España: Instituto de Mayores y Servicios Sociales (IMSERSO).

Islam, M.S., Baker, C., Huxley, P., Russell, I.T., \& Dennis, M.S. (2017). The nature, characteristics and associations of care home staff stress and wellbeing: a national survey. BMC nursing, 16(22). doi: 10.1186/s12912$017-0216-4$

Jagger, C. (2017, Sep 25). Living longer, but with more care needs: late-life dependency and the social care crisis [Blog post]. Retrieved from http://blogs.lse.ac.uk/politicsandpolicy/the-social-care-crisis-anddependency/

Karacsony, S. Chang, E., Johnson, A., Good, A., \& Edenborough, M. (2018). Assessing nursing assistants' competency in palliative care: An evaluation tool. Nurse education in practice, 33, 70-76. doi: 10.1016/j.nepr.2018.09.001
Kelly, C., \& Bourgeault, I. L. (2015). The personal support worker program standard in Ontario: An alternative to self-regulation? Healthcare Policy, 11(2), 20-26. from https://www.ncbi.nlm.nih.gov/pmc/articles/PMC4729280/

Lobo, A., Pérez-Echevarria, M. J. \& Artal, J. (1986). Validity of the scaled version of the General Health Questionnaire (GHQ-28) in a Spanish population. Psychological Medicine, 16, 135-140.

Losada, A., Montorio, I., Izal, M. \& Márquez, M. (2006). Estudio e intervención sobre el malestar psicológico de los cuidadores de personas con demencia. El papel de los pensamientos disfuncionales [Study and intervention on the psychological distress of caregivers of people with dementia. The role of dysfunctional thoughts]. Madrid, España: IMSERSO.

Losada, A., Shurgot, R., Knight, B.G., Márquez, M., Montorio., I., Izal, M., ... Ruiz, M.A. (2006). Cross-Cultural study comparing the association of familialism with burden and depressive symptoms in two samples of Hispanic dementia caregivers. Aging and Mental Health, 10(1), 69-76. doi: 10.1080/13607860500307647

Maslach, C., Jackson, S. E., \& Leiter, M. P. (1996). Maslach Burnout Inventory Manual (3rd ed.). Mountain View, CA: CPP, Inc.

Ravenswood, K., Douglas, J., \& Haar, J. (2018). Physical and verbal abuse, work demands, training and job satisfaction amongst aged-care employees in the home and community sector. Labour \& Industry: a journal of the social and economic relations of work, 27(4), 302-318, doi: 10.1080/10301763.2018.1427846

Rosenthal, R. (1991). Meta-analytic procedures for social research (2nd ed.). Newbury Park, CA: Sage.

Ruiz-Robledillo, N., \& Moya-Albiol, L. (2015). Effects of a cognitivebehavioral intervention program on the health of caregivers of people with autism spectrum disorder. Psychosocial Intervention, 24, 33-39. doi: 10.1016/j.psi.2015.01.001.

Saavedra, J., Bascón, M., Arias, S., Calderón, M., \& Mora, D. (2013). Women caregivers of dependent relatives and health: Effects of the participation in a stress mamagement workshop. Clínica y Salud, 24(2), 85-93. doi: $10.5093 / \mathrm{cl} 2013 \mathrm{a} 10$

Saavedra, J., Bascón, M.J., Rojas, M.J., \& Sala, A. (2014). Psychosocial health of family caregivers and professionals: Association with sociodemographic and psychological factors. Anuario de Psicología/The UB Journal of Psychology, 44(2), 229-243.

Schneider, J. (2017). Paid Caregivers: a new research challenge. Aging \& Mental Health, 21(7), 758-760. doi: 10.1080/13607863.2016.1156049.

Spector, A., Revolta, C., \& Orrell, M. (2016). The impact of staff training on staff outcomes in dementia care: a systematic review. International Journal of Geriatric Psychiatry, 31, 1172-1187. doi: 10.1002/gps.4488.

Wasserstein, R.L. \& Lazar, N. A. (2016). The ASA's statement on p-values: context, process, and purpose, The American Statistician. doi: 10.1080/00031305.2016.1154108.

Wilberforce, M., Abendstern, M., Tucker, S., Ahmed, S., Jasper, \& R. Challis, D. (2017). Support workers in community mental health teams for older people: roles, boundaries, supervision and training. Journal of Advanced Nursing, 73(7), 1657-1666. doi: 10.1111/jan.13264

Zhang, Y., Punnett, L., \& Nannini, A. (2017). Work-Family Conflict, Sleep, and Mental Health of Nursing AssistantsWorking in Nursing Homes. Workplace Health and Safety, 65(7), 2965-303. doi: $10.1177 / 2165079916665397$ 